\title{
How to Assess Policy Impact in National Energy and Climate Plans
}

\author{
Lauma BALODE ${ }^{1 *}$, Kristiāna DOLGE ${ }^{2}$, Peter D. LUND ${ }^{3}$, Dagnija BLUMBERGA ${ }^{4}$ \\ 1,2,4 Institute of Energy Systems and Environment, Riga Technical University, Azenes iela 12/1, \\ Riga, LV-1048, Latvia \\ ${ }^{3}$ Aalto University School of Science, PO Box 15100, FI-00076, Aalto, Espoo, Finland
}

\begin{abstract}
It is the responsibility of each member state of the European Union, to prepare a national energy and climate plan and set achievable climate targets and meaningful measures and policies to achieve the targets set. Annex 4 of the Latvian National Energy and Climate Plan for 2030 (hereinafter - NECP) provides an overview of policies and measures to achieve the climate targets. The NECP does not provide information on the impact of the policies or which measures are more important and which are less crucial Similarly, the measures in Annex 4 of the NECP were not determined by industry experts but by ministry officials, therefore, it is not clear whether the proposed measures will achieve the set climate targets, a point also made by European Commission in its evaluation report on NECP. The aim of the study is to develop a tool for the early assessment of the impact of energy and climate policy measures. The study developed a methodology to pre-assess the impacts of the policies identified in the NECP, impacts were described by measures effectiveness and stage of development. With this methodology, it is possible to assess the impact of energy policies using indicators to characterize the effectiveness of the policy and the level of development. The study confirmed that both the multi-criteria analysis and composite index method can be used as methods. The results showed that high impact measures were related to the promotion of energy efficiency in buildings, but low impact measures were comprehensive horizontal measures such as measures related principle 'energy efficiency first' and review of energy efficiency obligation schemes. The indicators with the highest impact on sustainability rate were possible side effects and transparency of policies.
\end{abstract}

Keywords - Energy and climate plans; energy policies; composite sustainability index; impact assessment; multi-criteria decision method

\section{INTRODUCTION}

The policies with the energy sector of the member states of the European Union (EU) are strongly influenced by the joint policy decision at EU level, which provide the framework for increasing the use of renewable energy, improving energy efficiency and reducing the greenhouse gas emissions. Over the past decade, numerous policies, regulations, and guidelines have been put into place to support these aims [1], [2]. The European Union recognizes the importance of energy efficiency for reaching its ambitious climate policy goals, which also has many co-benefits such as improving energy security and energy access, enhancing industrial competitiveness and reducing greenhouse gas emissions [3], [4].

\footnotetext{
* Corresponding author.

E-mail address: Lauma.Balode@rtu.lv
} 
The key driver of EU energy efficiency policy is Directive 2012/27/EU on energy efficiency (hereinafter - EED) [5]. The EED was adopted to achieve higher climate targets for the European Union by 2030 [6]. In line with the principles of the Energy Union, one of the main objectives of the energy policy of the European Union is to increase energy efficiency and reduce dependence on energy imports. The current policy agenda is based on the comprehensive integrated climate and energy policy adopted by European Council, which aims to improve energy efficiency by $32.5 \%$ by 2030 [5].

In December 2019, the European Union adopted the European Green Deal, to achieve full decarbonisation by 2050 [7]. In December 2020, the European Green Deal agreed that by 2030, greenhouse gas emissions should be reduced by $55 \%$ - compared to 1990 levels [8][10]. In the Green Deal, energy efficiency has been assessed as one of the most important drivers for achieving the climate goals of the European Union [6], [10], [11]. To jointly achieve the climate targets set, it is the responsibility of each member states of the European Union, to develop national energy and climate plan [6]. The European Union is currently facing energy import dependency and the need to limit climate change. It is evaluated that energy efficiency measures can cost-effectively reduce greenhouse gas emissions and mitigate growing climate change [12], [13]. Energy efficiency must be improved throughout the chain, from production to final energy consumption. In the field of energy efficiency, many of the measures taken at European Union are in areas where the greatest energy savings can be reach, such as buildings renovation [14].

Policymakers have a responsibility to implement policy instruments that meet the goals of transitioning to a low-carbon economy, but policies pursued and enforcement mechanisms used are not always very effective and often fail to meet the climate goals set by policymakers. Therefore, one of the key pillars of energy policy is understanding the political uncertainties and the main drivers of disputes that hinder the achievement of climate goals. There are situations where the government does not adequately consider all factors that may affect the broader outcome [10], [15].

The NECP is a long-term energy and climate policy planning document that sets out the basic principles, measures and directions of Latvia's state energy and climate policy for the next ten years. According to the NECP, the long-term goal is to improve public welfare and energy security by developing a carbon-neutral economy in a sustainable, cost-effective and competitive manner. To achieve the objectives of the plan, it is necessary to reduce the unsustainable use of resources (fossil fuels) by facilitating the transition to the use of renewable energy resources. To achieve the targets of the NECP, the plan includes twelve courses of action including improving: Improving energy efficiency and promoting the use of RES technologies in heating and cooling; promoting the use of zero-emission technologies in electricity generation, improving the greening of the tax system and the friendliness of energy efficiency and RES technologies. According to the NECP, Latvia plans to reduce GHG emissions by $65 \%$ by 2030 compared to emissions levels in 1990 [16]. According to the NECP, in developing the plan it was necessary to consider predictable factors, such as economic cyclicality, as well as unpredictable factors, political changes and geopolitical development scenarios. The NECP includes an economic assessment of the impact of the measures included in the plan, such as the investment required to implement the measures, information on cost-effectiveness, and a socio-economic impact assessment. According to the NECP assessment, the investment required to implement the planned policy measures for the period from 2021 to 2030 reach 8.2 billion ( $2.7 \%$ of GDP). The measures requiring the largest investments are energy efficiency improvement of buildings (EUR 1.7 billion), energy efficiency and renewable energy measures in district heating and cooling (EUR 1.6 billion), energy sector decarbonisation measures (EUR 1 billion), development (EUR 988 million), 
energy infrastructure development (EUR 830 million). According to the NECP, the main source of funding is EU funding, which means that the implementation of measures will be directly affected by the available funding [16], [17].

To provide an objective assessment of the climate and energy plans prepared by each Member State, the European Commission has carried out assessments of these plans. The assessments provide an evaluation of each country's climate targets, the likelihood of achieving them, and the inadequacies of the plans. Shortcomings in the plans can act as blind spots, so an objective assessment by experts is necessary. According to the NECP and assessment of the European Commission, Annex 4 of the NECP contains a list of planned and existing actions, but the core of the issue is that there is no information on the impact of each measure or which measures are more significant, therefore it is not possible to assess clearly whether the proposed measures can achieve the objectives set. According to the European Commission assessment of the NECP, European Commission points out that most of the measures proposed in the plan to achieve the climate targets are existing measures that will continue in the coming years and may not be sufficient to achieve the set climate targets by 2030.

According to the assessment, the description of the measures is general and there is a lack of specific policy measures and measurable and quantified results. The Latvian NECP Annex four has not carried out an impact assessment for each proposed measure and does not provide measurable, achievable indicators, so it is hard to assess whether the measures will be implemented and what factors and barriers will affect the implementation of the measures. The NECP also does not indicate how much funding will be allocated to each of the specific measure, e.g. within the existing budget. Latvia has identified several energy efficiency measures in the NECP and existing measures in the plan and it would be necessary to emphasise new measures to achieve higher energy savings. Despite the proposed measures, the European Commission has stressed that the implementation of the measures and thus the achievement of the set targets will be significantly influenced by the availability of financial resources. Since the impact of the measures is not known, it is then difficult to estimate which measures will achieve the targets set in the NECP [17], [18].

Several contradictions in energy policy might hinder reaching Green Deal targets and can be identified by developing different methodologies and using different methods. In order to be able to assess in a timely manner whether the proposed measures will achieve the climate targets set, it is necessary to carry out a timely assessment of the impact of the policy measures on the basis of previously defined criteria. The aim of this study is to develop a methodology for early evaluation or pre-assessment of the impact of energy and climate policy measures using the example of measures from NECP Annex four. In the study, the impact was described by the policy measures development stage and measures effectiveness against climate targets. The methodology can be an important tool to address the problem mentioned in the assessment of the European Commission that the Latvian NECP does not provide information on the importance of policies and the impact of each policy on the achievement of climate targets. With the methodology of policy measures impact evaluation, it is possible to assess energy policies using indicators to characterize the impact and identify initial inconsistencies that may hinder the achievement of the set climate targets, which can help policymakers to avoid them. 


\section{METHODOLOGY}

\subsection{Approach to the Study}

A methodology is developed here for the pre-assessment of the energy efficiency measures identified in the NECP. The first step in the methodology section was the literature review, which helps to identify the main success and failure factors in the implementation, enforcement and monitoring of energy and environmental policies. Based on the literature review and minimum information availability in Annex four six indicators were identified and defined to characterize the success or failure of the policy.

First, based on the NECP, including Annex 4, outline and summary of energy efficiency measures was made. Based on both the literature review and the explanatory description of the NECP 2030 measures and the availability of information, six indicators were identified that could be used to assess the impact of energy efficiency measures. To evaluate the impact of the selected policy measures, expert surveys were developed to assess the weight of the indicators and rank the measures based on their impact. Afterwards, policy measures were classified into three groups according to the scores obtained from the expert ranking - strong measures, medium measures, weak measures (Fig. 1).

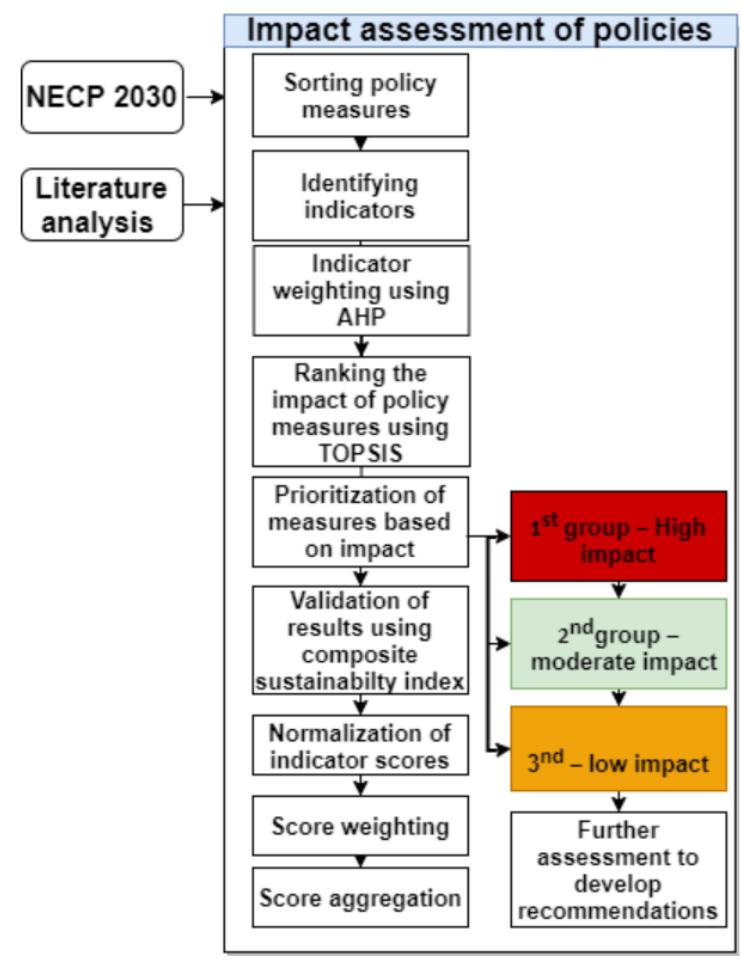

Fig. 1. Algorithm of methodology used in the study.

\subsubsection{Sorting Policy Measures}

Initially, measures related to energy efficiency were selected from Annex Four of the NECP 2030. The measures were selected based on the policy success factors described in more detail below, the minimum information available in the NECP, and the six indicators selected. An 
analysis was carried out of the information contained in Annex four of the NECP and throughout the plan on planned or existing measures to achieve the climate targets set in the EU.

\subsubsection{Identifying Indictors for Performance Assessment}

It was necessary to identify indicators that can be used to assess the impact of the measures set out in national policy documents and progress towards achieving the climate targets of the Green Deal. In addition, it was crucial to include indicators that could describe factors that may hinder the achievement of the objectives. The indicators must be such that it is possible to quantify the quality of the measures and determine whether these measures can achieve the objectives. The framework and fundamental basis of identifying indicators to assess the impact of policies were borrowed from the Better Regulation Agenda and the policy evaluation indicators [19], [20]. The indicators were first compiled, then selected and adapted to the research aim. Better regulation aims to promote open and transparent policy-making and provide comprehensive decision-making information [19], [21]. The OECD indicators for Regulatory Policy and governance are considered one of the most effective policy tools for achieving better political management [19], [20]. In order to obtain an objective policy evaluation in which policymakers can then apply the best decision-making process, it is necessary to select indicators that describe policy problems or uncertainties. The indicators should also describe whether the proposed policies are clearly defined, whether they are understandable to the public, and whether their purpose contributes to achieving the overall objectives [22]. Indicator possible side effects were borrowed from ODYSSEE-MURE project of the European Commission as one of the successfully implemented criteria for evaluating the impact of policy measures [23].

In order to assess the success of policies in achieving the objectives set, one of the ways is to evaluate the factors that determine the success or failure of actions. Policy success factors characterize the success mechanisms of particular policies. Policy success factors are determined by evaluating policy documents. A study [24] identified success and failure factors in policymaking. According to the findings, the chances of policy success are determined by key categories such as policy features, regulatory support, stakeholder engagement and financial support. The category of regulatory factors includes success factor such as ease of implementation, which is characterized by the political and practical feasibility of the measure with the resources allocated to it and within the deadline set. Success factors of financial support are, for example, long-term financing, which is characterized by the ability to provide funds for long-term policy measures. One of the success factors of financial support is also a stable budget for the implementation of planned policies, stable and predictable funding is provided for specific policies in each policy period. The category of policy characteristics includes important policy success factors such as clear goals and objectives, characterized by the fact that specific policy objectives are clearly defined and these policies are designed to achieve specific goals. The study used the OECD indicators of better regulation as well as considered the information on policy success and failure factors identified in the study [24].

Within the framework of the research, an analysis of the literature on the most important success and failure factors in the implementation, enforcement and monitoring of energy and environmental policy was performed [19]. Based on the literature review and minimal information availability of the policy description, six indicators were identified that could be used to characterize the stage of policy development and the success or failure of the policy. Following indicators were identified for NECP 2030 measures assessment - i1 Possible side effects describing whether there are blind spots, side effects that have not been assessed in 
the development of the policy and could be the reason why the set objectives cannot be achieved, e.g. fossil energy is indirectly promoted, or additional energy consumption is stimulated i2 Transparency characterizes the transparency of decision-making in the development of the specific policy and the potential influence of the lobby. i3 Objectivity describes whether measure is appropriate in terms of achieving climate goals and whether all stakeholders are involved, i4 Specificity- as indicator can be used to describe whether a specific, detailed and substantiated or general action plan has been developed and also describe action plan flexibility to changes. i5 Quality describes the long-term sustainability of the performance indicators and whether the achievable targets will not be limited to only specific measure but will contribute to a positive impact and chain reaction. i6 Funding describes whether the sources and amount of funding are clearly known and whether the funding is used to achieve the relevant objectives (Table 1).

TABLE 1. EXPLANATION OF INDICATORS FOR AN EXPERT ASSESSMENT

\begin{tabular}{lll}
\hline No. & Indicator & Explanation of the indicator \\
\hline i1 & Possible side & $\begin{array}{l}\text { Potential adverse side effects have been eliminated (no indirect support for } \\
\text { fossil energy resources has been created or additional energy consumption } \\
\text { stimulated) and the objective of the measure is fully in line with all the } \\
\text { basic principles of climate neutrality without coming into conflict with the } \\
\text { basic principles of sustainable development. A chain reaction is promoted } \\
\text { to identify and stimulate positive side effects (social economic impact, } \\
\text { environmental improvement, health effects, etc.). }\end{array}$ \\
\hline
\end{tabular}

i2 Transparency [24] Transparency in the decision-making and development of regulatory enactments is ensured. The potential influence of the lobby has been identified.

\begin{tabular}{llll}
\hline i3 & Objectivity [19], \\
[20] & & $\begin{array}{l}\text { Appropriate in terms of achieving climate targets. Stakeholders are fully } \\
\text { involved and opinions are discussed during the planning and } \\
\text { implementation of the specific measure. The action plan is acceptable to } \\
\text { relevant target groups and society. }\end{array}$ \\
\hline i4 & Specificity [24] & $\begin{array}{l}\text { A specific, detailed and substantiated (rather than general) action plan has } \\
\text { been developed, desired outcomes have been specified and those } \\
\text { responsible parties been clearly identified. If necessary, the plan provides } \\
\text { for the possibility of making changes as required. The plan is designed to } \\
\text { be flexible enough to be modified. If necessary, the plan provides for the } \\
\text { possibility of making changes as required. }\end{array}$ \\
\hline i5 & Quality [24] & $\begin{array}{l}\text { The long-term sustainability of the performance indicators envisaged in } \\
\text { the program (energy savings, emission reductions, transition to RES, etc.) } \\
\text { is ensured (the improvements achieved will not be limited to one measure, } \\
\text { but will contribute to a positive impact and chain reaction. }\end{array}$ \\
\hline i6 & Financing [24] & $\begin{array}{l}\text { Funding is allocated for the implementation of measures, the sources of } \\
\text { funding are clear and understandable, the amount of funding is appropriate } \\
\text { and justified for the implementation of measures. Funding is provided for } \\
\text { measures that will have an impact on reducing greenhouse gas emissions. }\end{array}$ \\
& &
\end{tabular}

Each indicator was rated on a scale of one to five, according to the Severity rating scale [25] where a score of 1 reflects Very low performance, 2 - Low performance, 3 - Moderate performance, 4 - High performance and 5 - Very high performance that significantly impacts the policy's success. The evaluation was carried out by nine industry experts and scientists who are high-level experts in energy efficiency issues and in the evaluation of environmental 
policy instruments. The expert assessment was based on observations made over several years in the energy efficiency and environmental management sector.

\subsection{Analytical Hierarchy Process}

The Analytical Hierarchy Process (hereinafter - AHP) method can be used as a component for indicators weighting for both composite sustainability index and Technique for Order Preference by Similarity to Ideal Solutions. AHP can be characterized as a decision-making tool that is widely used for various problem solving, including policy evaluation. AHP is used for evaluating different alternatives based on several criteria. AHP is a suitable tool for quantifying different criteria in other characteristic units that are difficult to quantify.

\subsubsection{Impact assessment for each of the indicators}

An expert assessment was required to compare each indicator's impact, with each indicator being assessed in relation to one of the other indicators. The assessment resulted in a 'weighting' of the indicator. To obtain this, experts were asked to complete an expert survey and place the score according to the rating scale. To assess the importance of each indicator, data was obtained using the AHP and expert surveys with specialists in the fields of environment and energy served as data sources. The experts were asked to rate the importance of the six indicators on a scale of one to nine, with 1 being equally important and nine being absolutely more important. The evaluation results in a 'weighting' of the indicator. AHP consists of a formulation phase, hierarchy structure, comparison of criteria pairs, weighting criteria and consistency checks. The main formulas for performing AHP are described below.

Calculation of normalized matrix using Eq. (1).

$$
X_{i j}=\frac{C_{i j}}{\sum_{i=1}^{n} C_{i j}},
$$

where

$X_{i j} \quad$ normalized pairwise value;

$C_{i j} \quad$ pairwise comparison value for each element;

$\sum C_{i j} \quad$ sum of pairwise comparison column [26].

Calculation of priority vector using Eq. (2).

$$
W_{i j}=\frac{\sum X_{i j}}{n},
$$

where

$\sum X_{i j} \quad$ normalized matrix column sum;

$n \quad$ number of criteria.

\subsection{Technique for Order Preference by Similarity to Ideal Solutions}

Technique for Order Preference by Similarity to Ideal Solutions (hereinafter - TOPSIS) is one of the multicriteria analysis methods and in study was used to validate the practical application of the developed model and to summarize the results of the expert evaluation. TOPSIS analysis is often used to rank alternatives and make an evaluation between them. Like the AHP method, TOPSIS analysis is used in a variety of fields, including policy evaluation. With the TOPSIS analysis it is possible to rank the measures as and for the weights by using the values previously obtained with AHP for each of the indicators. Therefore, 
TOPSIS analysis was the most appropriate method to accomplish the aim of the study. The main steps in conducting a TOPSIS analysis are selecting the criteria, determining the weights for the criteria using the AHP method or some other assessment of the importance of each indicator, then calculating the distance to the ideal and the nadir alternatives, and finally ranking the alternatives according to the results obtained. The main formulas used in the TOPSIS analysis are given below.

The values obtained in the decision matrix are normalized using Eq. (3).

$$
n_{i j}=\frac{x_{i j}}{\sqrt{\sum_{i=1}^{n} x_{i j}^{2}}},
$$

where $n_{i j}$ is normalized value, $i=1, j=1$.

The weights given show how important each of the criteria is compared to the other criteria. After normalization, the normalized matrix values are multiplied by the resulting weight for each of the indicators.

The weighted normalized decision matrix is calculated using Eq. (4).

$$
v_{i j}=w_{j} n_{i j}
$$

where

$v_{i j} \quad$ weighted normalized value;

$n_{i j} \quad$ normalized value;

$w_{j} \quad$ weight of the $j$-th criterion.

The next step was to calculate the distance to the ideal and anti-ideal solutions. Each of the weighted indicators is compared with the maximum and minimum value of the respective criterion.

The ideal distance from the ideal solution was calculated using Eq. (5).

$$
d_{a}^{+}=\sqrt{\sum_{j=1}^{n}\left(v_{i}^{+}-v_{a i}\right)^{2}},
$$

where $d_{a}^{+}$is distance to the ideal solution.

The distance to the anti-ideal solution was calculated according to Eq. (6).

$$
d_{a}^{-}=\sqrt{\sum_{j=1}^{n}\left(v_{i}^{-}-v_{a i}\right)^{2}},
$$

where $d_{a}^{-}$distance to the ideal solution.

The final step involves finding the relative volume and arranging alternatives using Eq. (7).

$$
C_{a}=\frac{d_{a}^{-}}{d_{\mathrm{a}}^{+}+d_{a}^{-}},
$$

where

$C_{a} \quad$ relative closeness to the ideal solution; 
$d_{a}^{-} \quad$ non-ideal or worst value;

$d_{a}^{+} \quad$ ideal or best value.

The result for each alternative ranges between 0 to 1 . The best alternative is the one closest to value 1 .

\subsection{Prioritization of Policies Based on Impact}

After ranking the policy measures with TOPSIS and AHP, the policy measures are prioritized according to their impact. The first group includes energy efficiency policies with scores above 0.70 (maximum score 1.0) and the highest score according to six indicators. The second group includes policies rated on a scale of 0.40 to 0.70 and belong to the mediumstrong policies, while group 3 includes policies currently rated as the weakest policies on a scale of 0-40 (Table 3).

TABle 2. Prioritisation Groups Based on ImPaCt of Policy MeAsures

\begin{tabular}{lll}
\hline Group No. & Scale (Max -1.0) & Group description \\
\hline Group No. 1 & More than 70 & High impact \\
Group No. 2 & More than 40-70 & Moderate impact \\
Group No. 3 & $0-40$ & Low impact \\
\hline
\end{tabular}

\subsection{Validation of Methodology Using Composite Sustainability Index}

To validate the developed methodology, the results obtained in the multi-criteria analysis were also tested using the composite sustainability index methodology. The composite index methodology, similar to the TOPSIS analysis, allows the inclusion of an unlimited number of indicators to measure different aspects and complex issues, such as sustainability, competitiveness, innovation. One of the advantages is that the sustainability index can be used in a wide range of cases and sectors, including policy makers in decision-making processes, which is the main focus of this study. With the help of the composite sustainability index, in addition to determining the ranking, it is also possible to clearly identify which of the indicators form the greatest impact on the sustainability of certain measures [27].

\subsection{Data Normalization}

Normalization was applied to standardize indicators to the same scale, therefore making indicators comparable between each other. The advantage of min-max normalization is that it ranks values in a range of $[0 ; 1]$, therefore making results easier to interpret [28].

Impact indicators were normalized using Eq. (8).

$$
I_{N, i j}^{+}=\frac{I_{a c t, j i}^{+}-I_{\min , j i}^{+}}{I_{\max , j i}^{+}-I_{\min , j i}^{+}},
$$

where

$I_{N, i j}^{+} \quad$ normalized value of impact indicator;

$I_{a c t, j i}^{+}$actual value of an indicator;

$I_{\min , j i}^{+}$minimal value of an indicator among all the policies; 
$I_{\max , j i}^{+}$maximum value of an indicator among all the policies;

$j \quad$ specific sub-indicator;

$i \quad$ specific indicator in particular sub-indicator.

\subsubsection{Weighting and Indicator Aggregation into Composite Sustainability Index}

After the sub-indices have been assigned the weight previously obtained with AHP, the sub-index aggregation must be performed using Eq. (9). The final composite sustainability index is then determined by accumulating the sum of each indicator with the relevant weight from the AHP using Eq. (9) [29].

$$
I_{S, j}=\sum_{j}^{n} W_{j} \cdot I_{N, i j}^{ \pm}, W_{i j}=\frac{1}{n_{i j}},
$$

where

$I_{S, j} \quad$ indicator sub-index value;

$W_{i j} \quad$ impact weight of indicators on sub-index (application of AHP weighting);

$n_{i j} \quad$ number of indicators;

$I_{N, i j}^{ \pm} \quad$ obtained normalized value of the indicator.

$$
I_{S C I}=\sum_{j}^{n} W_{j} \cdot I_{S, j},
$$

where

$I_{C S I} \quad$ composite sustainability index;

$W_{j} \quad$ impact weight of sub-index on composite sustainability index (determined from AHP) [26], [30].

\section{RESUltS AND DisCUSSION}

Using TOPSIS and AHP analysis, the impact analysis of most of the energy efficiency measures listed in Annex 4 of the NECP was carried out. According to the results of AHP, the greatest weight was given to possible effects $(0.30)$, transparency $(0.21)$, equal weight to the indicators objectivity and specificity $(0.15)$, lower weight to quality $(0.12)$, funding (0.07). Equal weights were then used to validate the results obtained in TOPSIS and it was found that this did not significantly change the results obtained. Using the AHP, a weight was assigned to each of the indicators.

After obtaining the results using TOPSIS, the measures were classified into three groups, as shown in Table 3. According to the results obtained, 4 out of 20 measures were rated with the high impact - RV.1.1. Continue to promote energy efficiency improvements in public buildings (0.90), RV.1.3. Continue to support energy efficiency improvements in municipal public buildings (0.85), RV.1.2. Continue to promote energy efficiency improvements in residential buildings $(0.84), H .14$. Develop research programs to promote research needed to achieve energy and climate goals $(0.80)$.

One of the reasons why these measures were rated with a high impact could be that they have been in place for years and have proven to be successful in existing projects, and all four measures are rated with a high impact and will continue. Another reason is that these measures 
are financed by various funds, which makes them more likely to be implemented. The Latvian NECP intends to continue projects to increase energy efficiency through the renovation of residential, state and municipal buildings. In the corresponding period, 2000 residential buildings and at least 5000 family houses are to be renovated.

According to European Commission, despite extensive renovations, this might not be enough to ensure decarbonisation of buildings by 2050 and the planned building improvement measures should be complemented by other concrete measures to remove obstacles to renovation. The European Commission points out that possible energy efficiency measures must be complemented by concrete measures to remove barriers to renovation. The plan foresees the installation of zero-emission renewable energy technologies and connection to district heating networks to achieve the targets, but results showed that these measures described in NECP currently are with moderate impact [17]. The majority or 12 of the 20 measures were assessed as moderate measures, this group includes measures related to renewable energy incentives and policies of taxes. Based on the analysis results, 4 low impact measures were evaluated and classified in the third group where the indicators do not exceed 0.4. Based on the evaluation of the six impact indicators, the following measures were classified under low impact: H.9. Evaluation the possibility of introducing energy savings trade (0.11), H.2. To review energy efficiency obligation scheme to facilitate the implementation of energy efficiency measures at large utilities and energy consumers (0.25), RV1.4. Implement energy efficiency improvement measures in private apartments or small building complexes, as well as promote efficient use of resources (0.32), H.1 Comprehensive implement and apply the principle of 'energy efficiency first' $(0.33)$. One of the reasons why horizontal measures rank in the third group could be that these measures are comprehensive and do not cover only one direction. The direction of actions includes more specific measures where the impact and expected outcome are easier to measure compared with horizontal measures that are less specific and describe the vision in general terms (Fig. 2).

The principle of 'energy efficiency first' has been assessed as a strategic priority of the European Union, which can reduce greenhouse gas emissions, improve security of energy supply, reduce energy imports and promote competitiveness in the European Union and refers to measure H.1 - Comprehensive implement and apply the principle of 'energy efficiency first' [6], [30]. According to the European Commission, the principle of 'energy efficiency first' should underpin all European energy policy, building on this principle and developing the necessary policies. The importance of the principle of 'energy efficiency first' means that energy policy decisions, planning and financial investment must first consider economically viable energy efficiency measures, with the emphasis on introducing measures that deliver energy savings [31]. The importance of the principle of 'energy efficiency first' is also highlighted in the Green Deal as one of the key instruments for achieving the 2050 decarbonisation targets [6], [32]-[34]. Latvia's NECP states that the principle of 'energy efficiency first' will be fully integrated into policy and investment planning processes before measures and investments are made. According to the NECP, the principle of 'energy efficiency first' has not been implemented in the political planning process and is not sufficiently considered when planning the necessary investments [16]. According to the assessment of the Latvian NECP by European Commission, it is highlighted that in order to achieve the required additional energy savings, additional policy measures are needed according to the 'energy efficiency first' principle [16].

The European Commission stresses that with the right measures in the buildings, industry and transport sectors, significant energy savings can be achieved and highlights in particular the importance of extending existing building renovation programs and Energy Efficiency Obligation programs (hereafter - EEOS) and this relates to measure H.2 - Review of the 
Energy Efficiency Obligation Scheme to facilitate the implementation of energy efficiency measures in large utilities and energy consumers. The obligation to establish an EEOS is set out in Article 7 of the EED. According to EEOS, each of the European Union member states must achieve a total energy saving of $0.8 \%$ from 2021 to the end of 2030 . To achieve the target, various energy efficiency measures must be introduced. The aim of the EEOS in Latvia is to promote the savings of the state's mandatory final energy consumption, the responsible parties are energy retail and distribution companies. Following the NECP, it was proposed to review the EEOS and extend it to ensure that the planned energy efficiency measures are implemented [16], [17], [35], [36]. Despite the assessment of European Commission that horizontal measures, including the 'energy efficiency first' principle and review of the Energy Efficiency Obligation Scheme, are particularly important for achieving energy efficiency targets, the measures currently described in the NECP energy report are assessed as having a low impact. Stronger efforts need to be made in order to improve the quality of the planning documents and action plans, otherwise a risk of failing to achieve the targets increases [35], [36].

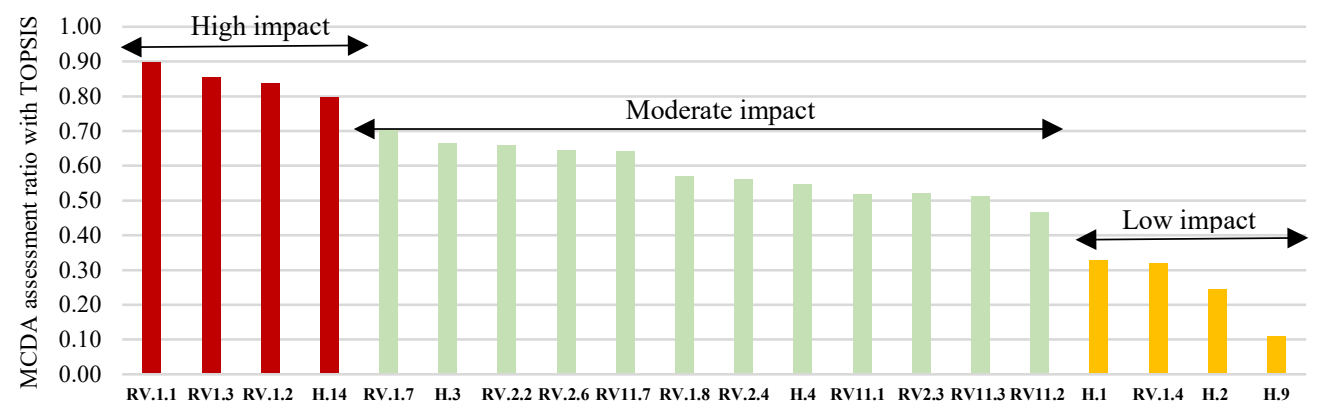

Energy efficiency measures

Fig. 2. Multi-criteria decision analysis results.

According to the obtained results from the validation of the results from the multi-criteria analysis with the composite sustainability index, the highest impact on sustainability is for possible side effects and transparency, followed by objectivity, specificity, quality and funding. The results showed that the highest sustainability index which can be described by the sustainability of the current policy implementation or development stage, is reached by the following policies: RV.1.1. Continue to promote energy efficiency improvements in public buildings (0.71), RV.1.3. Continue to promote energy efficiency improvements in municipal public buildings (0.70), RV.1.2. Continue to promote energy efficiency improvements in residential buildings $(0.70)$, and H.14. Develop research programs to promote research needed to achieve energy and climate goals (0.69), with the highest indicators formed by possible side effects -0.22 and 0.23 , and transparency -0.14 to 0.15 . In third place is the indicator objectivity -0.11 to 0.12 , while the lowest sustainability index was assessed for funding -0.04 to 0.05 . Consequently, the success of political measures is significantly influenced by the financial resources available to implement the respective measures.

A similar distribution applies to measures rated as low impact - H.9 assessing the possibility of introducing energy saving trading - sustainability index 0.46, H.2 reviewing the Energy Efficiency Obligation system to facilitate the implementation of energy efficiency 
measures among large utilities and energy consumers is rated with a second lower sustainability index -0.50 , followed by H.1 Comprehensive Implementation and Application of the principle of 'energy efficiency first' (0.51) and RV1.4. Implement energy efficiency measures in private residences or small building complexes and promote the efficient use of resources with a sustainability index of 0.53 . Composite sustainability index ranking was the same as TOPSIS. Therefore, the overall results produce the same conclusions (Fig. 3).

TABLE 3. ENERGy EFFICIENCY MEASURES IN FIG. 2

\begin{tabular}{|c|c|}
\hline RV.1.1 & Continue to promote the improvement of energy efficiency in public buildings \\
\hline RV1.3 & $\begin{array}{l}\text { Continue to support the introduction of energy efficiency improvement measures in } \\
\text { municipal buildings. }\end{array}$ \\
\hline RV.1.2 & Continue to promote energy efficiency improvements in residential buildings. \\
\hline H.14 & $\begin{array}{l}\text { Develop research programs to stimulate research needed to achieve energy and climate } \\
\text { targets. }\end{array}$ \\
\hline RV.1.7 & $\begin{array}{l}\text { Developing a long-term solution to improve the energy efficiency of Latvia's housing } \\
\text { stock. }\end{array}$ \\
\hline H.3 & $\begin{array}{l}\text { Strengthening agreements to improve energy efficiency, use of RES and promotion of } \\
\text { energy efficiency services, while supporting the conclusion and implementation of } \\
\text { agreements. }\end{array}$ \\
\hline RV.2.2 & $\begin{array}{l}\text { Promote the use of RES and improve energy efficiency in district heating. Adapt district } \\
\text { heating for cooling in buildings. }\end{array}$ \\
\hline RV.2.6 & $\begin{array}{l}\text { Supporting the development of innovative technologies and services to improve energy } \\
\text { efficiency in buildings, energy supply and production and RES. }\end{array}$ \\
\hline RV11.7 & Evaluate the system for applying the 'polluter pays' principle. \\
\hline RV.1.8 & Ensuring the attraction of investments for energy efficiency Measures of buildings \\
\hline RV.2.4 & $\begin{array}{l}\text { To promote the use of RES and the improvement of energy efficiency in local heating } \\
\text { and individual heating Implement and promote local and individual cooling system. }\end{array}$ \\
\hline H.4 & $\begin{array}{l}\text { Improving the accounting system for energy savings, monitoring and reporting on the } \\
\text { measures. }\end{array}$ \\
\hline RV11.1 & $\begin{array}{l}\text { Address the reduction of the tax burden on households for the implementation of energy } \\
\text { efficiency measures under the tax policy guidelines. }\end{array}$ \\
\hline RV.2.3 & $\begin{array}{l}\text { Promote the use of RES and improve energy efficiency in industry. Adjust district } \\
\text { heating for cooling buildings. }\end{array}$ \\
\hline RV11.3 & $\begin{array}{l}\text { Within the framework of tax policy guidelines to review excise tax rates and conditions } \\
\text { of their application to fuel. }\end{array}$ \\
\hline RV11.2 & $\begin{array}{l}\text { Within the framework of tax policy guidelines to review natural resource tax rates and } \\
\text { conditions of their application }\end{array}$ \\
\hline H.1 & Completely implement and apply the principle of «energy efficiency first» \\
\hline RV1.4 & $\begin{array}{l}\text { Implement energy efficiency improvement measures in private homes or small building } \\
\text { complexes, as well as promote efficient use of resources }\end{array}$ \\
\hline Н.2 & $\begin{array}{l}\text { Review of the Energy Efficiency Obligation Scheme to facilitate the implementation of } \\
\text { energy efficiency measures in large energy suppliers and energy consumers }\end{array}$ \\
\hline H.9 & Evaluate the possibility of introducing energy savings trade. \\
\hline
\end{tabular}


Latvia in the NECP has identified a number of measures to increase energy efficiency and existing measures. However, the proposed measures, the European Commission has stressed that the availability of funding will significantly influence the implementation of the measures. Consequently, energy efficiency measures are directly influenced by how funds are allocated [17] H.2. To review energy efficiency obligation scheme to facilitate the implementation of energy efficiency measures at large utilities and energy consumers. According to the NECP, only two voluntary agreements were concluded in 2017 . While the relevant ministry has the possibility to support certain energy efficiency improvement measures and energy audits under the agreement, there is no funding from the state budget or the State Energy Efficiency Fund [17].

The unknown information about funding sources, funding level and availability, and the quality and sustainability of the developed policies or documents may lead to the failure to achieve the climate targets.

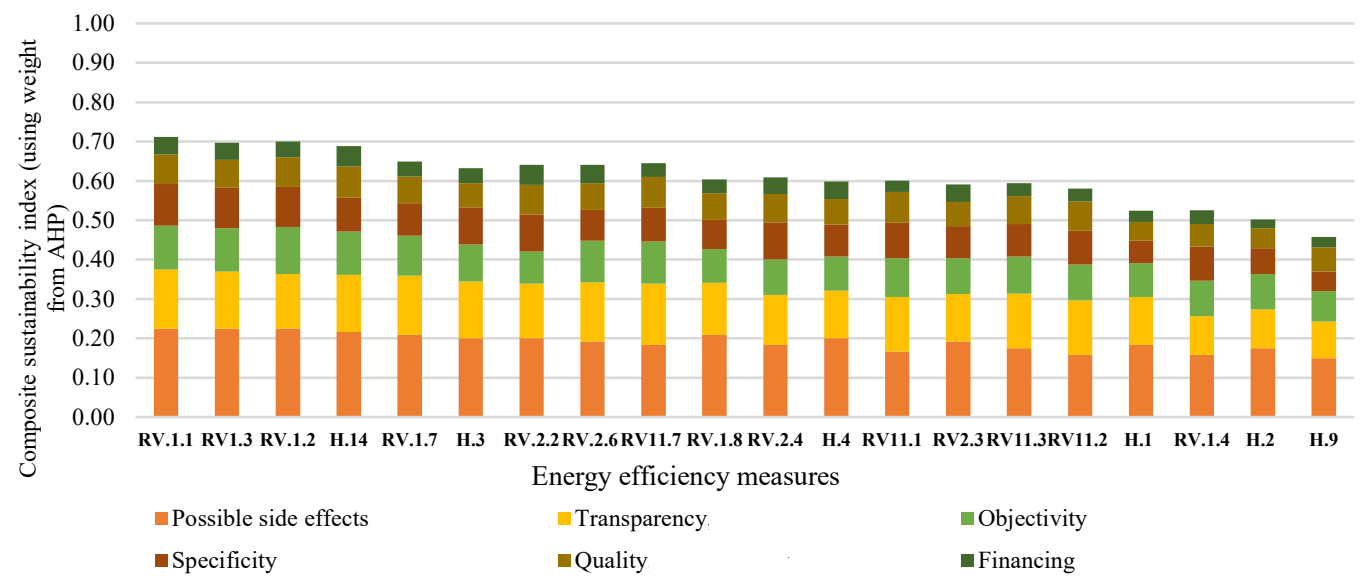

Fig. 3. Composite sustainability index of energy efficiency policies.

One of the recommendations could be to review and specify the horizontal measures envisaged. To achieve the set climate targets, it is necessary to think not only about improving energy efficiency in public, municipal and residential buildings, but to introduce new measures, including the use of RES in district heating. Four measures face high risk of failing to achieve the climate targets. Studies showed that in order to achieve the set climate targets, measures are needed that relate to both energy efficiency and measures that can increase the share of use of RES, and only in combination can these measures achieve the best effect. Combining energy efficiency and renewable energy policies could reduce the energy demand generated by the use of fossil fuels, while bringing economic benefits [4], [9].

\section{Conclusions}

The analysis of development stage of energy efficiency measures showed that high impact measures have a significant amount of funding and different funding sources, focus on improving the energy efficiency of buildings. The study showed that the measures with a high assessed development stage relates to the further improvement of energy efficiency in buildings, which are already existing and ongoing measures, as well as the development of a research programs to achieve climate goals. The highest sustainability indicators were 
possible side effects and transparency of the selected indicators, which means that these two indicators have a higher impact on sustainability. When performing a sensitivity analysis, one of the indicators that both increased and decreased the values of the measures depending on the assigned weight also were possible side effects. Increasing the weight of the indicator specification significantly increases the values of measure RV.1.4 Implement energy efficiency improvement measures in private homes or small building complexes, as well as promote efficient use of resources, which initially was assessed as a low-impact measure. The lowest impact on sustainability was for quality of policies or documents developed, and funding. In the sensitivity analysis, increasing the quality weight for low impact measures significantly decreased the values of measures H.1 and H.2, from which it can be concluded that the quality indicator is, however, one of the indicators that influence the success of the measures. As the sources of funding are often unclear, the level of funding for the implementation of certain policies may not be reported or the funding may come from the government budget. Overall, it is difficult to identify only one indicator that has the most impact of measuring success in achieving climate targets, that's depend on specific measures and indicators and indicators affect each other and need to be considered in combination.

With Low impact were assessed measures such as H.2. Review the Energy Efficiency Obligation system to facilitate the implementation of energy efficiency measures in large utilities and energy consumers (0.25), RV1.4. Implement energy efficiency measures in private apartments or small building complexes and promote efficient use of resources $(0.32)$, H.1. Comprehensive implement and apply the principle of 'energy efficiency first' (0.33). Contrary to the assessment of European Commission, the lowest impact of the measures concerned horizontal measures such as energy efficiency first and the revision of energy efficiency obligation programmes. One of the reasons why the horizontal measures H.1 and H.2 were assessed relatively lower than the other indicators could be that the horizontal measures cover several action lines and are less specific compared to the measures described in the action lines. Also, the financial resources available for the implementation of specific measures are not clearly indicated and the quality of the measures developed in general is indicated with low sustainability indicators. The measures classified as high development stage do not conflict with Green Deal and the climate targets and will be important for achieving the climate targets set, but measures assessed as low-impact run counter to the objectives of the Green Deal. With the methodology of policy development stage evaluation, it is possible to evaluate energy policy measures using indicators to characterize the impact and identify initial contradictions that may hinder the achievement of the set climate targets, which can help policy makers to avoid them. The study confirmed that it is equally possible to use the multi-criteria analysis to evaluate policies, as well as the composite sustainability index used to validate the methodology developed. One of the additional benefits of using the composite sustainability index is the ability to determine how much and which factor contributes to the overall value.

Policy makers can use the pre-evaluation methodology to assess the impact of policies defined for both macro and micro level policy documents. It is recommended that policy makers develop a pre-assessment system with specific criteria to assess whether a policy measure is consistent with the policy document and climate objectives before any measure is included in the plan. First, a form with specific criteria should be created. The information obtained can be used to integrate into the system dynamics model to develop further scenarios for policy development to achieve climate targets. The aim is to provide experts and officials with clear criteria to assess and forecast the impact of policies and compliance with established European Union and national climate targets through early impact assessment of policies. This could improve experts '/ officials' understanding of the factors influencing the 
success of measures so that partial or total non-compliance can be avoided in a timely manner. Limitations of the study are the limited information in Annex 4 of the NECP, which did not allow the inclusion of other indicators against which high impact measures could be assessed. Although there is a possibility for subjectivity in the experts' assessment, almost all experts identified the same high-impact measures and one, and the same low-impact measures and high impact measures. One of the factors influencing the research results could be the definition of indicators and the use of the AHP method. In order to obtain the most objective results, indicators must be accurately selected and defined in the first place. Moreover, in order to improve the accuracy of the results obtained, instead of using the AHP method, it is possible to include an additional table in the expert surveys, asking the experts to assign a weight to each indicator, (total value $100 \%$ ) and to use the average values of each indicator for further analysis.

\section{ACKNOWLEDGEMENT}

This research was funded by the Latvian Council of Science, project 'Blind spots in the energy transition policy (BlindSpots)', project No. 1zp-2018/2-0022.

\section{REFERENCES}

[1] Li M., Patiño-Echeverri D., Zhang J. Policies to promote energy efficiency and air emissions reductions in China's electric power generation sector during the 11th and 12th five-year plan periods: Achievements, remaining challenges, and opportunities. Energy Policy 2019:125:429-444. https://doi.org/10.1016/j.enpol.2018.10.008

[2] Rammer C., et al. Does energy policy hurt international competitiveness of firms? A comparative study for Germany, Switzerland and Austria. Energy Policy 2017:109:154-180. https://doi.org/10.1016/j.enpol.2017.06.062

[3] Phylipsen G. J. M. Phylipsen Climate Change Consulting Energy Efficiency Indicators Best practice and potential use in developing country policy making. Utrecht: Phylipsen Climate Change Consulting, 2010.

[4] Irena. Synergies between Renewable Energy and Energy Efficiency: A working paper based on REmap 2030. Abu Dhabi: IRENA, 2015.

[5] European Parliament. Energy policy: general principles. Fact Sheets The European Parliament [Online]. [Accessed 22.04.2021]. Available: https://www.europarl.europa.eu/factsheets/en/sheet/68/energetikas-politika-visparejieprincipi

[6] European Commission. Combined Evaluation Roadmap / Inception Impact Assessment. Brussles: European Commission, 2020.

[7] Huang H-T. Decentralized Energy: Grassroots, Participatory Forms and Mutual Shaping with Regional Economies in the cases of Freiburg, Higashi-Ohmi and YuanLi. Doktorarbeit. Freiburg: Freiburg Universitat https://doi.org/10.6094/UNIFR/14951

[8] Rissman J., et al. Technologies and policies to decarbonize global industry: Review and assessment of mitigation drivers through 2070. Applied Energy 2020:266:114848. https://doi.org/10.1016/j.apenergy.2020.114848

[9] US EPA. Part One: The Multiple Benefits of Energy Efficiency and Renewable Energy. Washington: EPA, 2019.

[10] European Commission. A European Green Deal | European Commission. Brussels: European Commission, 2019.

[11] European Commission. Communication From The Commission To The European Parliament, The European Council, The Council, The European Economic And Social Committee And The Committee Of The Regions. European Commission, 2019.

[12] European Commission. Directive 2012/27/EU of the European Parliament and of the Council of 25 October 2012 on energy efficiency, amending Directives 2009/125/EC and 2010/30/EU and repealing Directives 2004/8/EC and 2006/32/EC Text with EEA relevance. Oficcial Journal of the European Union 2012:L 315/1.

[13] European Commission. Energy efficiency directive | Energy [Online]. [Accessed 22.04.2021]. Available: https://ec.europa.eu/energy/topics/energy-efficiency/targets-directive-and-rules/energy-efficiency-directive_en

[14] European Commission. Energy efficiency targets | Energy [Online]. [Accessed 19.04.2021]. Available: https://ec.europa.eu/energy/topics/energy-efficiency/targets-directive-and-rules/eu-targets-energy-efficiency_en

[15] Balode L., Dolge K., Blumberga D. The Contradictions between District and Individual Heating towards Green Deal Targets. Sustainability 2021:13(6):3370. https://doi.org/10.3390/su13063370

[16] Cabinet of Ministers. Latvia's National Energy And Climate Plan 2021-2030. Riga: Cabinet of Ministers, 2020.

[17] European Commision. Assessment of the final national energy and climate plan of Latvia. Brussels: European Commission, 2020. 
[18] Aboltins R., et al. Are hugs, carrots and sticks essential for energy policy: A study of Latvia's national energy and climate plan. Environmental and Climate Technologies 2020:24(2):309-324. https://doi.org/10.2478/rtuect-2020-0075

[19] Schultzt R., et al. Regulation:, Better Indicators For Better Experience, The OECD iREG. 2019.

[20] European Commision. Better regulation Toolbox. 2017 [Online]. [Accessed 18.04.2021]. Available: https://ec.europa.eu/info/law/law-making-process/planning-and-proposing-law/better-regulation-why-andhow/better-regulation-guidelines-and-toolbox/better-regulation-toolbox en

[21] European Commision. COMMISSION STAFF WORKING DOCUMENT Better Regulation guidelines - impact assessment. [Accessed 16.04.2021]. Available: https://ec.europa.eu/info/law/law-making-process/planning-andproposing-law/better-regulation-why-and-how/better-regulation-guidelines-and-toolbox_en

[22] Coglianese C. Measuring Regulatory Performance. Evaluating The Impact Of Regulation And Regulatory Policy.Paris: OECD, 2012.

[23] ODYSSEE-MURE. Successful Energy Efficiency Policies Tool [Online]. [Accessed 16.04.2021]. Available: https://www.measures.odyssee-mure.eu/successful-efficiency-measures-tool.html\#/methodology

[24] Warren P. Demand-Side Management Policy: Mechanisms for Success and Failure. London: UCL Energy Institute, 2015.

[25] Barnum C. Usability Testing Essentials. Elsevier Inc., 2011.

[26] Waris M., et al. An application of analytic hierarchy process (ahp) for sustainable procurement of construction equipment: Multicriteria-based decision framework for malaysia. Mathematical Problems in Engineering 2019:6391431. https://doi.org/10.1155/2019/6391431

[27] Lemke C., Bastini K. Embracing multiple perspectives of sustainable development in a composite measure: The Multilevel Sustainable Development Index. Journal of Cleaner Production 2020:246:118884. https://doi.org/10.1016/j.jclepro.2019.118884

[28] Kyn P., Upadhyaya S., Nice T. Composite index as a measure on achieving Sustainable Development Goal 9 ( SDG9) industry-related targets : The SDG-9 index. Applied Energy 2020:265:114755. https://doi.org/10.1016/j.apenergy.2020.114755

[29] Barrera-Roldán A., Saldívar-Valdés A. Proposal and application of a Sustainable Development Index. Ecological Indicators 2002:2(3):251-256. https://doi.org/10.1016/S1470-160X(02)00058-4

[30] Triantaphyllou E. Using the analytic hierarchy process for decision making in engineering applications: Some challenges. The International Journal of Industrial Engineering: Theory, Applications and Practice 1995:2(1):35-44.

[31] European Commision. Regulation (EU) 2018/1999 of the European Parliament and of the Council of 11 December 2018 on the Governance of the Energy Union and Climate Action, amending Regulations (EC) No 663/2009 and (EC) No 715/2009 of the European Parliament and of the Council, Directives 94/22/EC, 98/70/EC, 2009/31/EC, 2009/73/EC, 2010/31/EU, 2012/27/EU and 2013/30/EU of the European Parliament and of the Council, Council Directives 2009/119/EC and (EU) 2015/652 and repealing Regulation (EU) No 525/2013 of the European Parliament and of the Council. Official Journal of the European Union 2018: L328/1.

[32] European Parliament. Energy efficiency [Online]. [Accessed 22.04.2021]. Available: https://www.europarl.europa.eu/factsheets/en/sheet/69/energoefektivitate

[33] European Commision. Energy efficiency first: accelerating towards a 2030 objective of 32.5\% [Online]. [Accessed 19.04.2021]. Available: https://ec.europa.eu/info/news/energy-efficiency-first-accelerating-towards-2030-objective2019-sep-25 en

[34] European Commision. Making Energy Efficiency First principle operational [Online]. [Accessed 19.04.2021]. Available: https://cordis.europa.eu/project/id/839509

[35] Cabinet of Ministers. Energy Efficiency Law. Latvijas Vèstnesis 2016:52.

[36] Cabinet of Ministers. Regulations Regarding the Energy Efficiency Obligation Scheme. Latvijas Vēstnesis 2017:97. 